\title{
Changes in hemoglobin profile reflect autologous blood transfusion misuse in sports
}

\author{
Nicola Lamberti ${ }^{1}$. Alessia Finotti ${ }^{2}$. Jessica Gasparello ${ }^{2}$. Ilaria Lampronti ${ }^{2} \cdot$ Christel Zambon ${ }^{1}$. \\ Lucia Carmela Cosenza ${ }^{2}$. Enrica Fabbri ${ }^{2} \cdot$ Nicoletta Bianchi $^{2} \cdot$ Francesca Dalla Corte $^{3} \cdot$ Maurizio Govoni $^{3}$. \\ Roberto Reverberi ${ }^{3} \cdot$ Roberto Gambari $^{2} \cdot$ Fabio Manfredini ${ }^{1}[0$
}

Received: 31 January 2018 / Accepted: 16 March 2018 / Published online: 23 March 2018

(c) SIMI 2018

\begin{abstract}
The changes in hemoglobin $(\mathrm{Hb})$ profile following autologous blood transfusion (ABT) for the first time were studied for anti-doping purposes. Twenty-four healthy, trained male subjects (aged 18-40) were enrolled and randomized into either the transfusion (T) or control (C) groups. Blood samples were taken from the T subjects at baseline, after withdrawal and reinfusion of $450 \mathrm{ml}$ of refrigerated or cryopreserved blood, and from $\mathrm{C}$ subjects at the same time points. Hematological variables (Complete blood count, Reticulocytes, Immature Reticulocytes Fraction, Red-cell Distribution Width, OFF-hr score) were measured. The $\mathrm{Hb}$ types were analyzed by high-performance liquid chromatography and the Hemoglobin Profile Index (HbPI) arbitrarily calculated. Between-group differences were observed for red blood cells and reticulocytes. Unlike $\mathrm{C}$, the $\mathrm{T}$ group, after withdrawal and reinfusion, showed a significant trend analysis for both hematological variables (Hemoglobin concentration, reticulocytes, OFF-hr score) and $\mathrm{Hb}$ types (glycated hemoglobin-HbA1c, HbPI). The control charts highlighted samples with abnormal values ( $>3$-SD above/below the population mean) after reinfusion for hematological variables in one subject versus five subjects for $\mathrm{HbAlc}$ and $\mathrm{HbPI}$. A significant ROC-curve analysis (area $=0.649, p=0.015$ ) identified a HbA1c cut-off value $\leq 2.7 \%$ associated to $100 \%$ specificity of blood reinfusion (sensitivity $25 \%$ ). Hemoglobin profile changed in trained subjects after ABT, with abnormal values of $\mathrm{HbA1c}$ and $\mathrm{HbPI}$ in $42 \%$ of subjects after reinfusion. Future studies will confirm the usefulness of these biomarkers in the anti-doping field.
\end{abstract}

Keywords Hemoglobins $\cdot$ Biomarkers $\cdot$ Doping in Sports $\cdot$ Blood transfusion autologous

Nicola Lamberti and Alessia Finotti are co-first authors.

Electronic supplementary material The online version of this article (https://doi.org/10.1007/s11739-018-1837-7) contains supplementary material, which is available to authorized users.

Roberto Gambari

roberto.gambari@unife.it

$\triangle$ Fabio Manfredini

fabio.manfredini@unife.it

1 Section of Sport Sciences, Department of Biomedical and Surgical Specialties Sciences, University of Ferrara, Italy, Via Gramicia 35, 44124 Ferrara, Italy

2 Section of Biochemistry and Molecular Biology, Department of Life Sciences and Biotechnologies, University of Ferrara, Italy, Via Fossato di Mortara 74, 44124 Ferrara, Italy

3 Immunohematological and Transfusional Service, University Hospital of Ferrara, Via Aldo Moro 8, Ferrara, Italy

\section{Introduction}

The unavailability of a method to detect the misuse of autologous blood transfusion (ABT), a prohibited performanceenhancing method in sport, led researchers to focus on the effects of ABT to identify markers enabling its indirect detection [1-3]. Abnormal changes in hematological parameters such as hemoglobin $(\mathrm{Hb})$ or OFF-hr score, which are identified following longitudinal evaluation by an adaptive model, are the basis for the athlete biological passport (ABP) hematological module $[4,5]$ that was adopted by the World Anti-Doping Agency.

Considering the potential confounding factors affecting hematological parameters (altitude, physiological fluctuations, and masking actions) $[3,6,7]$ and the limited usefulness of the OFF-hr score [8], novel biomarkers to enable increased sensitivity and specificity of the ABP have been recently proposed [9-12]. Actually, following blood 
manipulation, withdrawal, and reinfusion, the changes in oxygen availability may generate integrated molecular responses including changes of the components of the $\mathrm{Hb}$ profile. Fetal hemoglobin $(\mathrm{HbF})$, which differs in structure from adult $\mathrm{Hb}$, is normally present at very low levels $(0.0-0.9 \%)$ in adults [13] but its synthesis can be induced by hypoxia or pharmacological stimulation causing hypoxia $[14,15]$ with a possible link through the hypoxia-inducible factor system. Slight $\mathrm{HbF}$ changes have been observed in physiological [16, 17], pathological, or stressful conditions including blood transfusion [18-20]. Variations were also observed for glycated hemoglobin (HbA1c) following donation of autologous blood for elective surgery or red blood cell transfusion [21, 22]. However, the $\mathrm{Hb}$ profile has never been tested for anti-doping purposes. This study, as a part of the project "Novel Molecular biomARkers for detection of autologous blood transfusion in sport: fetal HemOglobin and microRNAs (MARATHON)", aims to determine whether changes in $\mathrm{HbF}$ levels and in the $\mathrm{Hb}$ profile occur following blood withdrawal and reinfusion, and whether they represent potential biomarkers that are useful in the anti-doping field for $\mathrm{ABT}$ detection.

\section{Methods}

The subjects were contacted for a possible enrollment in the study via information sheets distributed to university students participating in sports groups. The inclusion criteria included Caucasian male subjects with an age between 18 and 40, healthy conditions, adequate training level ( $>4 \mathrm{~h} /$ week), not participating in competitions of any level during the period of the study. The exclusion criteria included current smoking, anemia or altered blood counts at baseline, diabetes, hypotension and continuous use of medications.

Subjects satisfying the inclusion criteria and providing written informed consent were randomized into two groups via a simple randomization process with an allocation ratio of 1:1 between the transfusion ( $\mathrm{T}$ ) and control (C) groups. The study was approved by the Ethics Committee of Ferrara (number: 06/2014).
For both groups, seriated blood samples were obtained (Fig. 1), corresponding to three study periods: (1) baseline: day -40 (D-40); (2) withdrawal: day -25 (D-25), day -15 (D-15), and day 0 (D0); (3) reinfusion: day $+3(\mathrm{D}+3)$; day $+6(\mathrm{D}+6)$; day $+15(\mathrm{D}+15)$;

Blood samples also collected at D-35 and at D +35 were not considered for the study being potentially influenced by dilution (hyper hydration before withdrawal) or variations of training status or smoking habits, respectively.

Venous blood samples from an antecubital vein were drawn into four $5-\mathrm{mL}$ and one $2.7-\mathrm{mL}$ collection tubes (Sarstedt S-Monovette, Sarstedt AG, Nuembrecht, Germany) containing ethylenediaminetetraacetate (EDTA) as an anticoagulant. From each volunteer in the T group, one bag $(450 \mathrm{ml})$ of blood was collected at D-35. The blood was either refrigerated $(n=6)$ or cryopreserved $(n=6)$ until reinfusion, which was performed 35 days after donation (D0). Packed red blood cells (RBCs) and plasma samples were isolated and $\mathrm{RBCs}$ stored at $4{ }^{\circ} \mathrm{C}$ in SAGM (storage solution composed of saline, adenine, glucose, mannitol) or at $-80{ }^{\circ} \mathrm{C}$ (cryopreserved group) until reinfusion. Refrigerated blood was carefully warmed to $37{ }^{\circ} \mathrm{C}$ before reinfusion, whereas cryopreserved blood was defrosted and treated according to the international standard of transfusion medicine procedures, that were followed for all the interventional procedures.

At the day corresponding to blood withdrawal and autologous reinfusion, subjects in the $\mathrm{T}$ group were asked to avoid stressful conditions and heavy training sessions, and to maintain an adequate nutritional status. Before blood donation, participants were recommended to drink about $400 \mathrm{ml}$ of water and to have a light breakfast, avoiding milk and its products. All the procedures were performed between 7:30 and 11:00 AM, by unblinded qualified personnel at the Blood Transfusion Service of Ferrara, Azienda OspedalieroUniversitaria Ferrara.

The EDTA samples underwent a full blood count analysis using a fully automated hematology analyzer (Sysmex XE-2100, Sysmex, Norderstedt, Germany) at Laboratorio analisi chimico-cliniche e microbiologia of the Azienda Ospedaliera-Universitaria Ferrara. The parameters measured included $\mathrm{RBCs}, \mathrm{Hb}$ concentration $[\mathrm{Hb}]$, hematocrit
Fig. 1 Study design. $T$ transfusion, $C$ controls

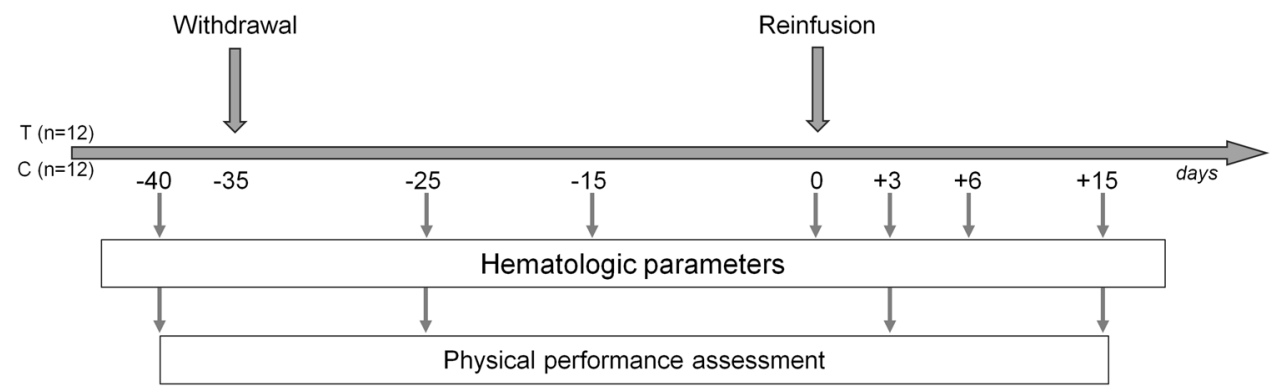


(HCT), mean corpuscular volume (MCV), mean corpuscular hemoglobin $(\mathrm{MCH})$, mean corpuscular hemoglobin concentration (MCHC), white blood cells (WBC), platelets (PLT), reticulocytes (Ret), immature reticulocytes fraction (IRF), red cells distribution width (RDW), and OFF-hr score (calculated as $[\mathrm{Hb}]$ divided by a constant value of 60 multiplied by the square root of reticulocytes).

The complete $\mathrm{Hb}$ analysis performed by high-performance liquid chromatography (HPLC) allowed the identification of the following $\mathrm{Hb}$ types: $\mathrm{HbF}$; $\mathrm{HbA}$; $\mathrm{HbA} 2$; glycated hemoglobin $(\mathrm{HbA} 1 \mathrm{c})$; and $\mathrm{Hb} \mathrm{A} 1 \mathrm{~d}$ aldimine fraction (HbA1d). To enable an overall analysis of the profile, the Hemoglobin Profile Index (HbPI) was arbitrarily determined by calculating the ratio between the product of $\mathrm{HbA}$ and $\mathrm{HbA} 2$ values and $\mathrm{HbA} 1 \mathrm{c}$.

For each sample, EDTA-treated whole blood was harvested $(100 \mu \mathrm{l})$ and washed once with sterile $1 \times$ Dulbecco's phosphate-buffered saline (DPBS). The cells were then lysed by adding $\mathrm{H}_{2} \mathrm{O}$ (dilution 1:10 v/v), vortex mixed, incubated on ice for $20 \mathrm{~min}$, and centrifuged at $12,000 \times g$ for $5 \mathrm{~min}$. The hemolysate supernatant was separated from the membrane debris, diluted in $\mathrm{H}_{2} \mathrm{O}$ (1:5) and injected $(20 \mu \mathrm{l})$ onto the column. Hb proteins present in the lysates were separated by cation-exchange HPLC (PolyCAT-A column), using a Beckman Coulter Instrument System Gold 126 Solvent Module-166 Detector (Brea, CA, USA). Samples were eluted in a solvent gradient using aqueous sodium chloride-BisTris-KCN buffers and detection was performed at $415 \mathrm{~nm}$. The standard controls were the purified $\mathrm{HbA}$ (Sigma, St. Louis, MO, USA) and HbF (Alpha Wassermann, Milano, Italy) [23, 24]. Values of HbF below the lower limit of quantitation were substituted with an arbitrary score of 0.01 .

\section{Statistical analysis}

Data are presented as the mean \pm standard deviation for continuous variables or number and percentage for categorical variables. Data distribution was tested using the Kolmogorov-Smirnov test. A baseline between-groups comparison was performed using the Student's $t$ test or a Mann-Whitney $U$ test, as appropriate. Within-group testing was performed using the paired Wilcoxon test, while the betweengroup comparison of all parameters was performed using an analysis of variance (ANOVA) or a Kruskal-Wallis test, as appropriate.

Trend analyses of hematologic and $\mathrm{Hb}$ profile parameters were performed via a repeated measures ANOVA. The analysis of hematological variables and $\mathrm{Hb}$ types that showed significant changes in the between- and withingroup analyses, was implemented with control charts to identify samples of $\mathrm{T}$ subjects with values exceeding 2- and 3-standard deviations (SD) from the entire non-treated population (mean of all values of $\mathrm{C}$ group and of values at D-40 for the T group). Samples with values exceeding the cut-off set for each parameter were labelled as atypical (>2-SD) or abnormal (>3-SD).

Receiver operating characteristic (ROC) curves were calculated to assess sensitivity and specificity of HbA1c to verify whether the variations of this parameter observed in the reinfusion phase may be of potential interest in the ABT detection. ROC curves were performed comparing samples free from any treatment (all samples of $\mathrm{C}$ athletes and samples at D-40 of $\mathrm{T}$ subjects) to samples following reinfusion (D $+3, D+6$ and $D+15$ of $T$ group).

A value of $p \leq 0.05$ was considered significant. Data were analyzed using Medcalc 18.0 (MedCalc Software bvba, Ostend, Belgium).

\section{Results}

\section{Subjects and interventions}

Thirty subjects were contacted for a possible enrollment in this study, and 24 of them met the inclusion criteria and were randomized into $\mathrm{T}$ and $\mathrm{C}$ groups. At baseline, the two groups did not differ in terms of anthropometric variables, training hours and directly measured maximal oxygen consumption (Table 1). The enrolled subjects underwent blood sample collection as scheduled by the timeline proposed.

\section{Hematological parameters and hemoglobin types at baseline}

At baseline, both hematological variables and the five components of the $\mathrm{Hb}$ profile did not differ between groups (Tables 2, 3). None of the components of $\mathrm{Hb}$ profile was significantly correlated with other blood parameters at baseline.

\section{Hematological parameters and $\mathrm{Hb}$ types after withdrawal and reinfusion: group analysis}

As expected, RBC, [Hb], HCT, and OFF-hr score significantly decreased after blood withdrawal and increased after reinfusion in the $\mathrm{T}$ group, with significant differences between groups, particularly for the OFF-hr score at D-25 ( $p<0.001)$ (Table 2). A quadratic trend overtime was observed for $[\mathrm{Hb}](t=4.28 ; p=0.001)$, $\operatorname{Ret} \%(t=-3.50$; $p<0.001)$ and OFF-hr $(t=4.00 ; p=0.001)$ in subjects of the T group. No differences were observed between the two T subgroups (cryopreserved versus refrigerated blood).

HPLC analysis was successfully performed and values of $\mathrm{HbF}$ were below the lower limit of quantitation for 88 out 
Table 1 Characteristics of the subjects included in the study

\begin{tabular}{|c|c|c|c|}
\hline & Transfusion $(n=12)$ & Control $(n=12)$ & $p$ \\
\hline \multicolumn{4}{|l|}{ Anthropometric } \\
\hline Age (years) & $25 \pm 3$ & $23 \pm 2$ & n.s. \\
\hline Height (m) & $1.79 \pm 0.07$ & $1.77 \pm 0.05$ & n.s. \\
\hline Weight (kg) & $79 \pm 11$ & $70 \pm 6$ & n.s. \\
\hline $\begin{array}{l}\text { Body mass index }(\mathrm{kg} / \\
\left.\mathrm{m}^{2}\right)\end{array}$ & $24.6 \pm 3.4$ & $22.3 \pm 2.2$ & n.s. \\
\hline \multicolumn{4}{|l|}{ Hematologic } \\
\hline $\mathrm{RBC}, \times 10^{6} / \mu \mathrm{L}$ & $5.11 \pm 0.44$ & $5.03 \pm 0.21$ & n.s. \\
\hline $\mathrm{Hb}, \mathrm{g} / \mathrm{dl}$ & $14.9 \pm 0.9$ & $15.1 \pm 0.6$ & n.s. \\
\hline HCT, \% & $44.0 \pm 2.2$ & $44.1 \pm 1.4$ & n.s. \\
\hline $\mathrm{MCV}, \mathrm{fL}$ & $86 \pm 4$ & $88 \pm 3$ & n.s. \\
\hline $\mathrm{MCH}, \mathrm{pg}$ & $29.3 \pm 1.4$ & $30.1 \pm 1.0$ & n.s. \\
\hline $\mathrm{MCHC}, \mathrm{g} / \mathrm{dL}$ & $33.9 \pm 0.9$ & $34.3 \pm 0.8$ & n.s. \\
\hline $\mathrm{WBC}, \times 10^{3} / \mu \mathrm{L}$ & $6.12 \pm 1.12$ & $6.18 \pm 1.22$ & n.s. \\
\hline $\mathrm{PLT}, \times 10^{3} / \mu \mathrm{L}$ & $228 \pm 72$ & $215 \pm 32$ & n.s. \\
\hline Reticulocytes, \% & $0.86 \pm 0.22$ & $0.87 \pm 0.17$ & n.s. \\
\hline IRF, \% & $5.5 \pm 3.2$ & $3.5 \pm 1.8$ & n.s. \\
\hline RDW, \% & $13.0 \pm 0.5$ & $12.8 \pm 0.5$ & n.s. \\
\hline OFF-hr score & $94.1 \pm 10.9$ & $95.6 \pm 9.1$ & n.s. \\
\hline Glycaemia, mg/dl & $84 \pm 8$ & $87 \pm 6$ & n.s. \\
\hline \multicolumn{4}{|l|}{ Sport parameters } \\
\hline Training hours/week & $8 \pm 3$ & $7 \pm 3$ & n.s. \\
\hline Sport vintage (years) & $15 \pm 5$ & $13 \pm 7$ & n.s. \\
\hline $\operatorname{Type}^{\mathrm{a}}$ (AE, AN, ALT) & $3-2-7$ & $3-3-6$ & n.s. \\
\hline $\mathrm{VO}_{2} \max (\mathrm{ml} / \mathrm{kg} / \mathrm{min})$ & $56.7 \pm 9.2$ & $59.1 \pm 6.1$ & n.s. \\
\hline
\end{tabular}

$R B C$ red blood cells, $H b$ hemoglobin, $H C T$ hematocrit, $M C V$ mean corpuscular volume, $\mathrm{MCH}$ mean corpuscular hemoglobin, $\mathrm{MCHC}$ mean corpuscular haemoglobin concentration, $W B C$ white blood cells, $P L T$ platelets, $I R F$ immature reticulocytes fraction, $R D W$ red cells distribution width, $A E$ aerobic, $A N$ anaerobic, $A L T$ aerobicanaerobic alternate, $\mathrm{VO}_{2}$ max maximal oxygen consumption

${ }^{a}$ Sports classification according to Dal Monte (1969)

of 168 samples collected. Considering the values at all time points (Table 3), between-group differences were not observed at any time. Sporadic within-group differences were observed for $\mathrm{HbF}, \mathrm{HbA}, \mathrm{HbA} 2$, and $\mathrm{HbA} 1 \mathrm{~d}$ particularly in the T group. Trend analyses performed for all $\mathrm{Hb}$ profile parameters, highlighted a significant trend for $\mathrm{HbA} 1 \mathrm{c}$ in $\mathrm{T}$ group (linear $t=-4.00 ; p=0.021$, with significant within-group differences observed at D+6 and D 15 respect to D-40 (Table 3 ).

For the calculated parameter, HbPI a significant linear trend $(t=2.53 ; p=0.028)$ was also observed, along with a significant within-group comparison for $\mathrm{T}$ subjects at $\mathrm{D}+6(p=0.047)$ respect to D-40. No differences were observed when comparing the two T subgroups.

\section{Hematological parameters and $\mathrm{Hb}$ types after withdrawal and reinfusion: identification of atypical and abnormal values}

The control charts of parameters which showed significant changes in the between- and within-group comparisons, highlighted abnormal absolute values in the reinfusion phase particularly for HbA1c (two subjects) and HbPI parameters (five subjects) respect to [Hb] (one subject), Ret\% (zero subjects) and OFF-hr score (one subject) (Fig. 2).

A different pattern for $\mathrm{Hb}$ profile changes of possible interest for the ABP management was frequently observed in the $\mathrm{T}$ group (Online Resource Figure 4). The analysis of each subject at the different time points for hematological parameters showed several atypical/abnormal values mainly located in the withdrawal phase (particularly at D-25) for 9 out of 12 subjects, rather than after reinfusion (4/12 subjects). On the contrary, HbA1c and HbPI showed a high number of atypical/abnormal values in the samples after reinfusion ( 7 out of 12 subjects) as well a delayed (20 days after blood donation) and weaker response after withdrawal (3/12 subjects) (Fig. 3).

The ROC analysis of HbA1c, to detect the blood reinfusion procedure performed, showed an area under curve of 0.649 ( $p=0.015 ; 95 \%$ CI $0.561-0.730)$ with sensitivity/ specificity of $50.0 / 82.2$ for values $\leq 3.32$ (positive/negative likelihood ratio of $2.82 / 0.61$ ). A $100 \%$ specificity was reached for $\mathrm{HbA} 1 \mathrm{c}$ values $\leq 2.7$ (sensitivity $25.0 \%$; negative likelihood ratio of 0.75 ) with possible detection of 5 out of 12 subjects of the T group (Online Resource Figure 5).

\section{Discussion}

This study has confirmed the hypothesis that after blood collection and autologous reinfusion, detectable changes in $\mathrm{Hb}$ species occur.

The change of hemoglobin profile (i) becomes evident 10 days after blood withdrawal and particularly after reinfusion, (ii) shows an individual pattern of response which reduces the statistical significance in the between-group analysis when comparing treated and controls, and (iii) exposes several subjects with atypical/abnormal values with respect to the mean values of the untreated population. Such behavior, of possible interest in the anti-doping field, differs from that of hematological parameters, that despite presenting average values significantly different between $\mathrm{T}$ and $\mathrm{C}$ groups, they do not exhibit individual values useful to discriminate treated subjects in the entire population after reinfusion. 
Table 2 Values of hematological parameters in the two groups for the different time points. Within- and between-group comparisons are shown

\begin{tabular}{|c|c|c|c|c|c|c|c|}
\hline Transfusion $(n=12)$ & D-40 & D-25 & D-15 & D0 (r) & $\mathrm{D}+3$ & $D+6$ & $D+15$ \\
\hline $\mathrm{RBC}, 10^{6} \mu 1^{-1}$ & $5.11 \pm 0.44$ & $4.78 \pm 0.37 * *$ & $4.90 \pm 0.32$ & $4.92 \pm 0.39$ & $5.25 \pm 0.42 * * * \dagger$ & $5.15 \pm 0.45^{* *}$ & $5.16 \pm 0.39 * *$ \\
\hline$[\mathrm{Hb}], \mathrm{g} \mathrm{dl}^{-1}$ & $14.9 \pm 0.9$ & $14.0 \pm 0.8^{* * \dagger}$ & $14.3 \pm 0.5 \dagger \dagger$ & $14.4 \pm 0.9$ & $15.2 \pm 0.8 * * *$ & $14.8 \pm 0.8^{*}$ & $14.9 \pm 0.8$ \\
\hline HCT, \% & $44.0 \pm 2.2$ & $41.3 \pm 2.1 * * \dagger$ & $42.3 \pm 1.6 \dagger$ & $42.5 \pm 2.4$ & $45.1 \pm 2.1 * * *$ & $44.2 \pm 2.6^{*}$ & $44.1 \pm 2.1^{*}$ \\
\hline $\mathrm{MCV}, \mathrm{fL}$ & $86 \pm 4$ & $86 \pm 3$ & $86 \pm 3$ & $86 \pm 3$ & $86 \pm 3$ & $86 \pm 3$ & $86 \pm 3$ \\
\hline $\mathrm{MCH}, \mathrm{pg}$ & $29.3 \pm 1.4$ & $29.3 \pm 1.3$ & $29.3 \pm 1.4$ & $29.2 \pm 1.3^{\dagger}$ & $29.1 \pm 1.1^{\dagger}$ & $28.9 \pm 1.4$ & $28.8 \pm 1.3^{*}$ \\
\hline $\mathrm{MCHC}, \mathrm{g} \mathrm{dl}^{-1}$ & $33.9 \pm 0.9$ & $33.9 \pm 0.6$ & $33.9 \pm 0.7$ & $33.9 \pm 0.7$ & $33.8 \pm 0.6$ & $33.6 \pm 1.0$ & $33.7 \pm 0.8$ \\
\hline $\mathrm{WBC}, 10^{3} \mu \mathrm{l}^{-1}$ & $6.12 \pm 1.12$ & $6.42 \pm 1.61$ & $6.47 \pm 1.70$ & $6.26 \pm 1.24$ & $6.49 \pm 1.51$ & $6.06 \pm 1.40$ & $6.11 \pm 1.49$ \\
\hline PLT, $10^{3} \mu 1^{-1}$ & $228 \pm 72$ & $244 \pm 61 * * *$ & $242 \pm 65^{*}$ & $241 \pm 72 *$ & $234 \pm 76$ & $227 \pm 64$ & $226 \pm 64$ \\
\hline Reticulocytes, \% & $0.86 \pm 0.22$ & $1.35 \pm 0.33 * * * \dagger$ & $1.11 \pm 0.27 * *$ & $0.96 \pm 0.35$ & $0.90 \pm 0.28$ & $0.74 \pm 0.17 * * \dagger$ & $0.79 \pm 0.29$ \\
\hline IRF, \% & $5.5 \pm 3.2$ & $8.4 \pm 3.1 * * * \dagger \dagger$ & $7.3 \pm 2.9 * *^{\dagger}$ & $6.0 \pm 3.6$ & $5.8 \pm 2.9$ & $4.2 \pm 2.0$ & $5.3 \pm 2.6$ \\
\hline RDW, \% & $13.0 \pm 0.5$ & $13.2 \pm 0.4 * * \dagger$ & $13.2 \pm 0.5^{\dagger}$ & $13.0 \pm 0.3$ & $13.0 \pm 0.4$ & $13.0 \pm 0.5$ & $13.0 \pm 0.4$ \\
\hline OFF-hr score & $94.1 \pm 10.9$ & $70.5 \pm 8.8^{* * * * \dagger \dagger}$ & $80.4 \pm 9.0^{\dagger \dagger}$ & $86.2 \pm 10.0$ & $96.1 \pm 12.0 *$ & $96.9 \pm 9.3 * *$ & $95.9 \pm 13.0^{*}$ \\
\hline Control $(n=12)$ & $\mathrm{D}-40$ & $\mathrm{D}-25$ & D-15 & D0 & $\mathrm{D}+3$ & $\mathrm{D}+6$ & $\mathrm{D}+15$ \\
\hline $\mathrm{RBC}, 10^{6} \mu \mathrm{l}^{-1}$ & $5.03 \pm 0.21$ & $4.94 \pm 0.26$ & $5.03 \pm 0.19$ & $5.00 \pm 0.22$ & $4.95 \pm 0.26^{*}$ & $4.96 \pm 0.24$ & $4.99 \pm 0.16$ \\
\hline$[\mathrm{Hb}], \mathrm{g} \mathrm{dl}^{-1}$ & $15.1 \pm 0.6$ & $14.8 \pm 0.8^{*}$ & $15.1 \pm 0.6$ & $15.1 \pm 0.7$ & $14.8 \pm 0.8 * *$ & $14.8 \pm 0.7$ & $14.8 \pm 0.4^{*}$ \\
\hline НCT, \% & $44.1 \pm 1.4$ & $43.1 \pm 1.9^{*}$ & $44.0 \pm 1.5$ & $43.8 \pm 1.6$ & $43.4 \pm 2.1^{*}$ & $43.4 \pm 2.1$ & $43.6 \pm 1.3^{*}$ \\
\hline $\mathrm{MCV}, \mathrm{fL}$ & $88 \pm 3$ & $87 \pm 3$ & $87 \pm 3$ & $87 \pm 2$ & $88 \pm 2$ & $88 \pm 2$ & $87 \pm 3$ \\
\hline $\mathrm{MCH}, \mathrm{pg}$ & $30.1 \pm 1.0$ & $29.9 \pm 0.9$ & $30.0 \pm 0.9$ & $30.2 \pm 0.9$ & $30.0 \pm 0.9$ & $29.9 \pm 1.1$ & $29.7 \pm 1.0^{*}$ \\
\hline $\mathrm{MCHC}, \mathrm{g} \mathrm{dl}^{-1}$ & $34.3 \pm 0.8$ & $34.2 \pm 0.6$ & $34.3 \pm 0.7$ & $34.5 \pm 0.7$ & $34.2 \pm 0.7$ & $34.2 \pm 0.7$ & $34.1 \pm 0.6$ \\
\hline WBC, $10^{3} \mu 1^{-1}$ & $6.18 \pm 1.22$ & $5.90 \pm 1.20$ & $6.08 \pm 1.77$ & $5.71 \pm 0.83$ & $5.99 \pm 1.49$ & $6.19 \pm 1.07$ & $6.25 \pm 1.28$ \\
\hline PLT, $10^{3} \mu \mathrm{l}^{-1}$ & $215 \pm 32$ & $212 \pm 35$ & $213 \pm 25$ & $219 \pm 30$ & $215 \pm 38$ & $221 \pm 36$ & $221 \pm 33$ \\
\hline Reticulocytes, \% & $0.87 \pm 0.17$ & $0.91 \pm 0.15$ & $0.99 \pm 0.27$ & $1.03 \pm 0.22$ & $0.89 \pm 0.19$ & $0.91 \pm 0.17$ & $0.98 \pm 0.26$ \\
\hline IRF, \% & $3.5 \pm 1.8$ & $4.6 \pm 1.8$ & $4.9 \pm 1.4$ & $4.9 \pm 1.5$ & $4.8 \pm 1.4$ & $5.3 \pm 2.0$ & $5.0 \pm 2.5$ \\
\hline RDW, \% & $12.8 \pm 0.5$ & $12.7 \pm 0.6$ & $12.8 \pm 0.5$ & $12.8 \pm 0.6$ & $12.9 \pm 0.6$ & $12.9 \pm 0.6$ & $12.9 \pm 0.5$ \\
\hline OFF-hr score & $95.6 \pm 9.1$ & $90.8 \pm 9.7$ & $91.6 \pm 10.3$ & $90.4 \pm 9.6$ & $91.8 \pm 8.7^{*}$ & $91.2 \pm 10.3$ & $89.4 \pm 8.1^{*}$ \\
\hline
\end{tabular}

$D$ days of blood collection, $r$ blood reinfusion, $R B C$ red blood cells, $[H b]$ hemoglobin concentration, $H C T$ hematocrit, $M C V$ mean corpuscular volume, $M C H$ mean corpuscular hemoglobin, $M C H C$ mean corpuscular hemoglobin concentration, WBC white blood cells, $P L T$ platelets, IRF immature reticulocytes fraction, $R D W:=$ red cell distribution width

Within-group comparison: paired samples Wilcoxon test. $* p<0.05 ; * * p<0.01 ; * * * p<0.001$

Between-group comparison: one-way analysis of variance. ${ }^{\dagger} p<0.05 ;{ }^{\dagger \dagger} p<0.01 ;{ }^{\dagger \dagger} p<0.00$

The analysis of $\mathrm{Hb}$ types in response to ABT, showed that $\mathrm{HbF}$ variations in the $\mathrm{T}$ group occurred in both phases of ABT treatment, but mainly following blood withdrawal, with values exceeding $0.8 \%$ observed only in two subjects of the $\mathrm{T}$ group. This observation confirms the responsiveness of this parameter to changes in the status determining hypoxia (e.g., high altitude or hypobaric chamber exposure) [14, 25]. An average trend for $\mathrm{HbF}$ to decrease following reinfusion was also observed, which is consistent with changes in this direction noted in the presence of an increase in oxygen availability [26]. Unfortunately, besides the expected modest increase in $\mathrm{HbF}$ levels, the statistical analysis was limited by the undetectable values observed at baseline in some subjects. Contrarily, HbA1c was easily detectable and quantifiable by HPLC analysis and showed readily measurable levels and interesting changes in response to ABT. HbA1c, a clinical biomarker routinely used to monitor long-term glycemic control in individuals with diabetes mellitus but with no current use in the anti-doping field, showed a decreasing trend following both blood withdrawal and especially after reinfusion unlike most of the hematological parameters (e.g., Hb, Ret\%, OFF-hr score) which exhibited a response characterized by opposite trends. A slightly not-significant decreasing trend due to $\mathrm{HbA} 1 \mathrm{c}$ fluctuations overtime was observed also in $\mathrm{C}$ group. However, these changes occurred in a range of values corresponding to a normal mean blood glucose level (around 80-90 mg/dl) unlike values around the lower limits observed in $\mathrm{T}$. These HbA1c values $(<2.7 \%$ by HPLC) correspond to a mean blood glucose level around $60-70 \mathrm{mg} / \mathrm{dl}$ [27] consistent with a prolonged hypoglycemia incompatible with a healthy status and acceptable training conditions. 
Table 3 Values of hemoglobin types in the two groups for the different time points

\begin{tabular}{|c|c|c|c|c|c|c|c|}
\hline Transfusion $(n=12)$ & D-40 & D-25 & D-15 & D0 (r) & $\mathrm{D}+3$ & $D+6$ & $D+15$ \\
\hline \multicolumn{8}{|l|}{ Measured } \\
\hline $\mathrm{HbF}$ & $0.27 \pm 0.30$ & $0.23 \pm 0.25$ & $0.35 \pm 0.38$ & $0.18 \pm 0.26$ & $0.13 \pm 0.16$ & $0.10 \pm 0.14$ & $0.11 \pm 0.17$ \\
\hline $\mathrm{HbA}$ & $89.3 \pm 0.9$ & $89.8 \pm 1.0$ & $90.2 \pm 2.1$ & $91.0 \pm 1.9^{*}$ & $90.5 \pm 1.2 * *$ & $90.7 \pm 1.9^{*}$ & $91.3 \pm 1.1 * * *$ \\
\hline $\mathrm{HbA} 2$ & $2.69 \pm 0.28$ & $2.60 \pm 0.30$ & $2.48 \pm 0.44$ & $2.31 \pm 0.56^{*}$ & $2.53 \pm 0.39$ & $2.80 \pm 0.94$ & $2.45 \pm 0.45$ \\
\hline $\mathrm{HbA1c}$ & $4.14 \pm 0.64$ & $4.04 \pm 0.49$ & $3.87 \pm 0.71$ & $3.67 \pm 0.80$ & $3.57 \pm 0.98$ & $3.44 \pm 1.00^{*}$ & $3.40 \pm 0.88^{* *}$ \\
\hline HbA1d & $3.63 \pm 0.37$ & $3.40 \pm 0.64$ & $3.06 \pm 1.10$ & $2.90 \pm 1.41 *$ & $3.25 \pm 1.24$ & $2.97 \pm 1.82$ & $2.78 \pm 0.95^{*}$ \\
\hline \multicolumn{8}{|l|}{ Calculated } \\
\hline HbPI & $59 \pm 10$ & $58 \pm 10$ & $58 \pm 9$ & $59 \pm 17$ & $69 \pm 22$ & $82 \pm 36^{*}$ & $71 \pm 25$ \\
\hline Control $(n=12)$ & D-40 & D-25 & D-15 & D0 & $\mathrm{D}+3$ & $\mathrm{D}+6$ & $D+15$ \\
\hline \multicolumn{8}{|l|}{ Measured } \\
\hline $\mathrm{HbF}$ & $0.21 \pm 0.32$ & $0.22 \pm 0.28$ & $0.15 \pm 0.21$ & $0.14 \pm 0.21$ & $0.23 \pm 0.30$ & $0.10 \pm 0.15$ & $0.08 \pm 0.12$ \\
\hline $\mathrm{HbA}$ & $89.5 \pm 0.6$ & $89.7 \pm 0.6$ & $90.1 \pm 1.6$ & $91.1 \pm 1.7 *$ & $90.3 \pm 1.1$ & $91.0 \pm 1.1^{*}$ & $90.9 \pm 1.5^{*}$ \\
\hline $\mathrm{HbA} 2$ & $2.84 \pm 0.27$ & $2.77 \pm 0.29$ & $2.58 \pm 0.29 *$ & $2.54 \pm 0.65$ & $2.67 \pm 0.30$ & $2.63 \pm 0.59$ & $2.38 \pm 0.46^{*}$ \\
\hline $\mathrm{HbA1c}$ & $4.10 \pm 0.49$ & $4.11 \pm 0.38$ & $4.09 \pm 0.88$ & $3.73 \pm 0.88$ & $4.08 \pm 0.56$ & $3.67 \pm 0.60$ & $3.69 \pm 0.57$ \\
\hline HbA1d & $3.40 \pm 0.19$ & $3.19 \pm 0.73$ & $3.11 \pm 1.09$ & $2.54 \pm 0.91 *$ & $2.76 \pm 0.62 *$ & $2.60 \pm 0.87 *$ & $2.99 \pm 1.08$ \\
\hline \multicolumn{8}{|l|}{ Calculated } \\
\hline $\mathrm{HbPI}$ & $63 \pm 11$ & $61 \pm 8$ & $59 \pm 14$ & $64 \pm 21$ & $60 \pm 10$ & $66 \pm 15$ & $59 \pm 13$ \\
\hline
\end{tabular}

Within- and between-group comparisons are shown

$D$ days of blood collection, $r$ blood reinfusion, $H b F$ fetal hemoglobin, $H b A 1 c$ glycated hemoglobin, $H b A l d$ aldimine fraction, $H b P I$ Hemoglobin Profile Index $\left(\mathrm{HbA}^{*} \mathrm{HbA} 2\right) / \mathrm{HbA} 1 \mathrm{c}$

All hemoglobin types are expressed in percentage of total hemoglobin

Within-group comparison: paired samples Wilcoxon test. ${ }^{*} p<0.05 ; * * p<0.01$; *** $p<0.001$

Between-group comparison: one-way analysis of variance. ${ }^{\dagger} p<0.05$; ${ }^{\dagger \dagger} p<0.01 ;{ }^{\dagger \dagger} p<0.001$

A decrease of $\mathrm{HbA1c}$ was previously reported following both blood collection, donation and reinfusion and attributed to a hyperdynamic state of hemoglobin due to blood volume loss following withdrawal and accelerated turnover of RBC [21] or bone marrow stress [22, 28]. Conditions affecting shortened erythrocyte survival or decreasing mean erythrocyte age were associated with low-HbA1c values [29]. RBC lifespan represents a determinant of percentage HbA1c and a heterogeneity in mean RBCs age in hematologically normal people both with and without diabetes with impact on $\mathrm{HbAlc}$ values was reported [30]. In our study, this heterogeneity may be amplified among $\mathrm{T}$ subjects, and within each treated subject, during the ABT phases for different factors. The release from the bone marrow of reticulocytes with a certain $\mathrm{HbA1c}$ level should be considered [30], being stimulated in the T group after withdrawal (Ret\% increase to $1.35 \%$ ) and downregulated after reinfusion (Ret\% decrease to $0.74 \%$ ). A possible early disappearance of a number of RBCs after transfusion might be also involved. Despite the insufficient understanding of the storage damage on RBC and their performance [31], RBCs during their stay in the blood bank become vulnerable to stressful conditions [32] with a reduced lifespan after reinfusion. A possible early disappearance of 5-15\% within the first $24 \mathrm{~h}$ after transfusion, and up to $25 \%$ or more for longer storage time [33] has been reported. As hypothesized, the effects of ABT-related changes in oxygen availability and of blood manipulation procedures might switch on integrated molecular responses. Besides altered $\mathrm{Hb}$ profiles, an overexpression of a pool of erythroid and HbF-related miRNAs only after ABT in a subgroup of athletes under study was observed [34 and unpublished data]. Therefore, the heterogeneity of RBCs age at baseline, and the different inter-individual erythropoietic responses to $\mathrm{ABT}$ may contribute to explain the abnormally low HbA1c values (below 2-SD and 3-SD of the average population) observed only in the $\mathrm{T}$ group in 5 and two out of 12 subjects, respectively. In the population under study, we also defined a reference value of $\mathrm{HbA} 1 \mathrm{c}$ with a criterion associated to a $100 \%$ specificity, potentially useful in the anti-doping field. Other $\mathrm{Hb}$ forms assessed by HPLC showed changes during the two ABT phases, and their integration in a parameter as HbPI exposed values 3-SD above the average of the whole untreated population only among transfused subjects up to 15 days after reinfusion.

The presence of an altered $\mathrm{Hb}$ profile in subjects receiving reinfusion of both refrigerated and cryopreserved blood, might support the analysis of the hematological parameters of the $\mathrm{ABP}$ for the $\mathrm{ABT}$ detection (Online 
Fig. 2 Control charts of hemoglobin concentration, reticulocytes, OFF-hr score, glycated hemoglobin and HbPI for both groups. The vertical line identifies the reinfusion period. $[H b]$ hemoglobin concentration, HbAlc glycated hemoglobin, HbPI Hemoglobin Profile Index, $S D$ standard deviation

Resource Figure 4). Moreover, the wide window of an altered profile may represent an added value for these parameters in the anti-doping field. Finally, the one-way decreasing trend of $\mathrm{HbAlc}$, which is evident in transfused subjects and particularly recognizable in the cryopreserved subgroup, may be of interest also in the case of frequent repeated procedures of blood collection and reinfusion of even small amounts of blood to bypass the ABP.

Unlike hematological variables, following $\mathrm{ABT}, \mathrm{Hb}$ types did not show significantly different average values compared to $\mathrm{C}$ group, but exhibited a wider range of changes compared to the baseline as well a high individual variability of response. This pattern may derive from the factors previously discussed, as well from factors not related to the treatment (training status, nutritional aspects, measurement issues, etc.). Hence confounding factors able to interfere with measurement or interpretation of HbA1c results are possible [29, 35], but the accuracy of $\mathrm{HbA} 1 \mathrm{c}$ measurement is preserved by HPLC even in the presence of genetic $\mathrm{Hb}$ variants or high $\mathrm{HbF}$ levels. However, the HPLC measurement here employed, makes difficult to compare the HbA1c value of this study with those obtained with methods routinely used in diabetes detection [27]. Other possible confounding factors related to chronic diseases (chronic renal failure, chronic liver disease) are not applicable to a healthy population competing at a high agonistic level. Changes of HbA1c observed in pregnancy and in iron deficiency or following iron replacement therapy should be considered [35].

We are aware that this study has several limitations. The sample size is limited for the analysis and includes only male Caucasian volunteers. This was intended to reduce the data variability, considering that the two different procedures of blood conservation might contribute to a lesshomogenous response in the $\mathrm{T}$ group.

In conclusion, for the first time, to the best of our knowledge, a study points out not quantitative but qualitative changes of the hemoglobin pattern following ABT. These changes were evident only in treated subjects, independently from blood conservation, in all the phases of ABT and especially in the reinfusion phase when the hematological variables were almost "silent" in terms of variations.

Novel parameters related to the study of $\mathrm{Hb}$ profile might be, therefore, suggestive of blood manipulation,

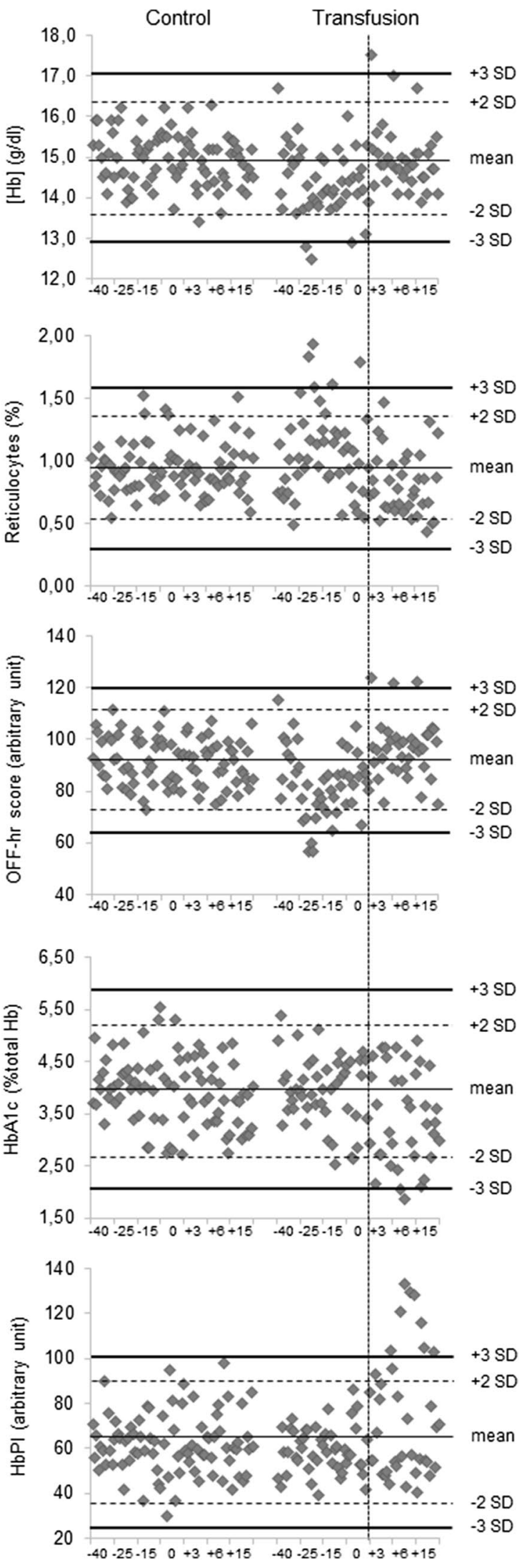



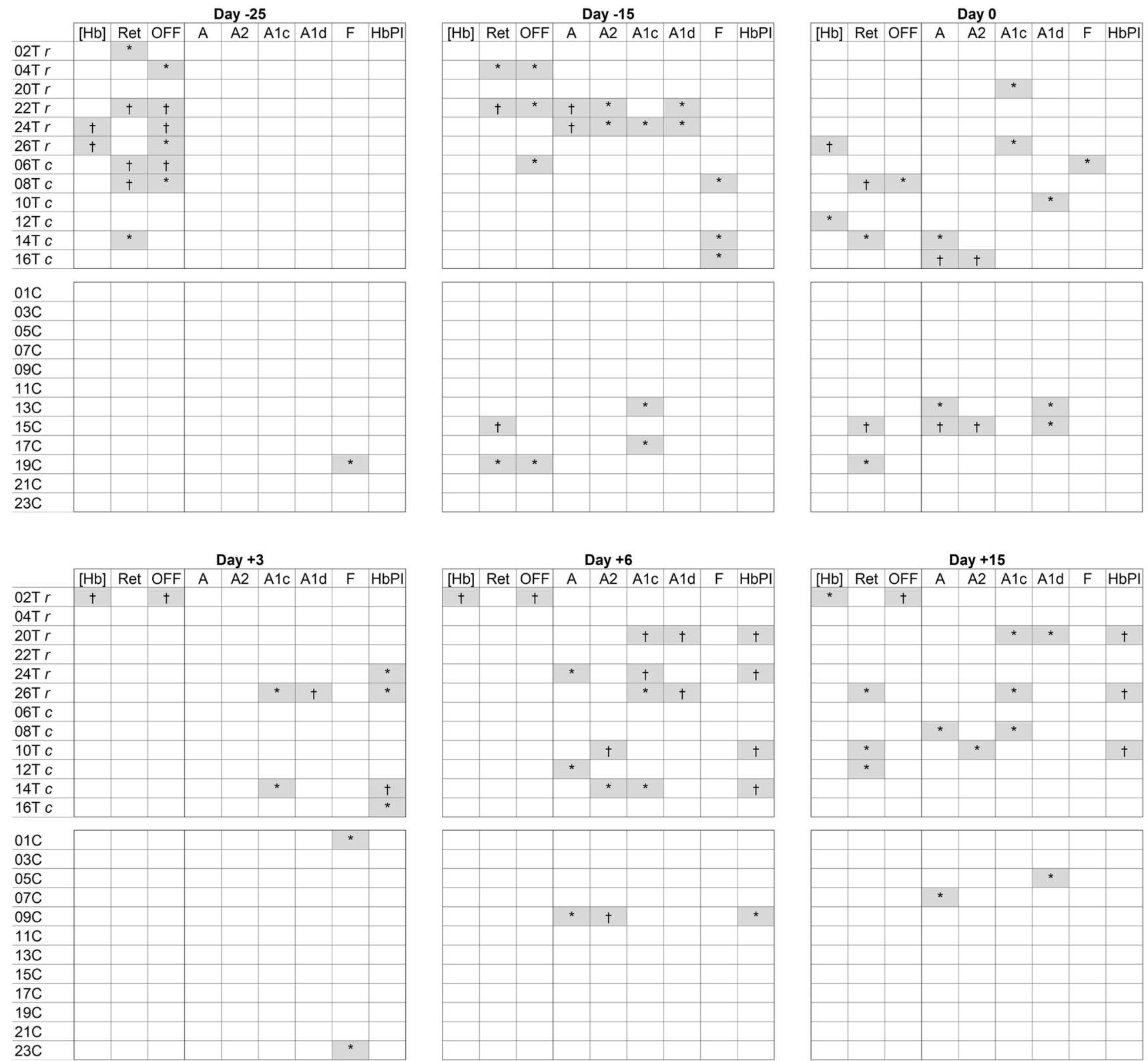

Fig. 3 Samples exceeding 2- $\left(^{*}\right)$ and 3-standard deviations ${ }^{\dagger}$ ) from the mean of all untreated samples at the different time points for each subject. $[\mathrm{Hb}]$, hemoglobin concentration, Ret reticulocytes, OFF OFF-hr score, $A$ hemoglobin-A, A2 hemoglobin-A2, A1c glycated

however, further studies to confirm their relevance as biomarkers of $\mathrm{ABT}$ are needed.

Acknowledgements We thank the personnel of immunohematological and transfusional service for their kind cooperation, and all the athletes that voluntarily participated in the study.

Funding This project has been carried out with the support of the World Anti-Doping Agency-Grant Number: 14C06FM. Funding source had no involvement in the trial conduction neither in the analysis and interpretation of the data. hemoglobin, Ald hemoglobin aldimine fraction, $F$ fetal hemoglobin, $H b P I$ Hemoglobin Profile Index, $S D$ standard deviation, $r$ refrigerated blood, $c$ cryopreserved blood, $\mathrm{T}$ transfusion group, $C$ control group

\section{Compliance with ethical standards}

Conflict of interest The authors declare that they have no conflict of interest.

Statement of human and animal rights All procedures performed were in accordance with the ethical standards of the institutional and/ or national research committee and with the 1964 Helsinki Declaration and its later amendments or comparable ethical standards. The study was approved by the Ethics Committee of Ferrara (06/2014). 
Informed consent Written informed consent was obtained from all the participants.

Data availability Research data reported in this manuscript are available at http://dx.doi.org/10.17632/2ypv6744p6.1.

\section{References}

1. Jelkmann W, Lundby C (2011) Blood doping and its detection. Blood 118(9):2395-2404. https://doi.org/10.1182/blood-2011-02303271

2. Mørkeberg J (2012) Detection of autologous blood transfusions in athletes: a historical perspective. Transfus Med Rev 26(3):199_ 208. https://doi.org/10.1016/j.tmrv.2011.09.007

3. Segura J, Lundby C (2014) Blood doping: potential of blood and urine sampling to detect autologous transfusion. Br J Sports Med 48(10):837-841. https://doi.org/10.1136/bjsports-2014-093601

4. Pottgiesser T, Sottas PE, Echteler T, Robinson N, Umhau M, Schumacher YO (2011) Detection of autologous blood doping with adaptively evaluated biomarkers of doping: a longitudinal blinded study. Transfusion 51(8):1707-1715. https://doi.org/10.11 11/j.1537-2995.2011.03076.x

5. Schumacher YO, Saugy M, Pottgiesser T, Robinson N (2012) Detection of EPO doping and blood doping: the haematological module of the Athlete Biological Passport. Drug Test Anal 4(11):846-853. https://doi.org/10.1002/dta.406

6. Salamin O, De Angelis S, Tissot JD, Saugy M, Leuenberger N (2016) Autologous Blood Transfusion in Sports: emerging Biomarkers. Transfus Med Rev 30(3):109-115. https://doi.org/10.1016/j. tmrv.2016.05.007

7. Guglielmini C, Casoni I, Patracchini M, Manfredini F, Grazzi G, Ferrari M, Conconi F (1989) Reduction of Hb levels during the racing season in nonsideropenic professional cyclists. Int J Sports Med 10(5):352-356. https://doi.org/10.1055/s-2007-1024927

8. Damsgaard R, Munch T, Mørkeberg J, Mortensen SP, GonzálezAlonso J (2006) Effects of blood withdrawal and reinfusion on biomarkers of erythropoiesis in humans: implications for antidoping strategies. Haematologica 91(7):1006-1008

9. Leuenberger N, Barras L, Nicoli R, Robinson N, Baume N, Lion N, Barelli S, Tissot JD, Saugy M (2016) Hepcidin as a new biomarker for detecting autologous blood transfusion. Am J Hematol 91(5):467-472. https://doi.org/10.1002/ajh.24313

10. Leuenberger N, Barras L, Nicoli R, Robinson N, Baume N, Lion N, Barelli S, Tissot JD, Saugy M (2016) Urinary di-(2-ethylhexyl) phthalate metabolites for detecting transfusion of autologous blood stored in plasticizer-free bags. Transfusion 56(3):571-578. https:// doi.org/10.1111/trf.13408

11. Nikolovski Z, De La Torre C, Chiva C, Borràs E, Andreu D, Ventura R, Segura J (2012) Alterations of the erythrocyte membrane proteome and cytoskeleton network during storage-a possible tool to identify autologous blood transfusion. Drug Test Anal 4(11):882890. https://doi.org/10.1002/dta.1342

12. Reichel C (2011) OMICS-strategies and methods in the fight against doping. Forensic Sci Int 213(1-3):20-34. https://doi.org/10.1016/j. forsciint.2011.07.031

13. Fairbanks VF, Klee GG (1999) Biochemical aspects of hematology. In: Burtis CA, Ashwood ER (eds) Tietz Textbook of Clinical Chemistry, 3rd edn. WB Saunders Company, Philadelphia, pp 1657-1669

14. Risso A, Fabbro D, Damante G, Antonutto G (2012) Expression of fetal hemoglobin in adult humans exposed to high altitude hypoxia. Blood Cells Mol Dis 48(3):147-153. https://doi.org/10.1016/j. bcmd.2011.12.004
15. Cao H (2004) Pharmacological induction of fetal hemoglobin synthesis using histone deacetylase inhibitors. Hematology 9(3):223233. https://doi.org/10.1080/10245330410001701512

16. Bureau MA, Shapcott D, Berthiaume Y, Monette J, Blouin D, Blanchard P, Begin R (1983) Maternal cigarette smoking and fetal oxygen transport: a study of P50, 2,3-diphosphoglycerate, total hemoglobin, hematocrit, and type F hemoglobin in fetal blood. Pediatrics 72(1):22-26

17. Bard H, Lachance C, Widness JA, Gagnon C (1994) The reactivation of fetal hemoglobin synthesis during anemia of prematurity. Pediatr Res 36(2):253-256. https://doi.org/10.1203/00006450-19940 8000-00018

18. Sarakul O, Vattanaviboon P, Tanaka Y, Fucharoen S, Abe Y, Svasti S, Umemura T (2013) Enhanced erythroid cell differentiation in hypoxic condition is in part contributed by miR-210. Blood Cells Mol Dis 51(2):98-103. https://doi.org/10.1016/j.bcmd.2013.03.005

19. Mabaera R, West RJ, Conine SJ, Macari ER, Boyd CD, Engman CA, Lowrey CH (2008) A cell stress signaling model of fetal hemoglobin induction: what doesn't kill red blood cells may make them stronger. Exp Hematol 36(9):1057-1072. https://doi.org/10.1016/j. exphem.2008.06.014

20. Schaeffer EK, West RJ, Conine SJ, Lowrey CH (2014) Multiple physical stresses induce $\gamma$-globin gene expression and fetal hemoglobin production in erythroid cells. Blood Cells Mol Dis 52(4):214-224. https://doi.org/10.1016/j.bcmd.2013.10.007

21. Sugimoto T, Hashimoto M, Hayakawa I, Tokuno O, Ogino T, Okuno M, Hayashi N, Kawano S, Sugiyama D, Minami H (2014) Alterations in $\mathrm{HbA} 1 \mathrm{c}$ resulting from the donation of autologous blood for elective surgery in patients with diabetes mellitus. Blood Trans 12(Suppl 1):s209-s213. https://doi.org/10.2450/2013.0271-12

22. Spencer DH, Grossman BJ, Scott MG (2011) Red cell transfusion decreases hemoglobin A1c in patients with diabetes. Clin Chem 57(2):344-346. https://doi.org/10.1373/clinchem.2010.157321

23. Ou CN, Rognerud CL (1993) Rapid analysis of hemoglobin variants by cation-exchange HPLC. Clin Chem 39(5):820-824

24. Bianchi N, Finotti A, Ferracin M, Lampronti I, Zuccato C, Breveglieri G, Brognara E, Fabbri E, Borgatti M, Negrini M, Gambari R (2015) Increase of microRNA-210, decrease of raptor gene expression and alteration of mammalian target of rapamycin regulated proteins following mithramycin treatment of human erythroid cells. PLoS One 10(4):e0121567. https://doi.org/10.1371/journ al.pone.0121567

25. Veith R, Papayannopoulou T, Kurachi S, Stamatoyannopoulos G (1985) Treatment of baboon with vinblastine: insights into the mechanisms of pharmacologic stimulation of $\mathrm{Hb} \mathrm{F}$ in the adult. Blood 66(2):456-459

26. Barkemeyer BM, Hempe JM (2000) Effect of transfusion on hemoglobin variants in preterm infants. J Perinatol 20(6):355-358

27. Karami A (2014) Baradaran A (2014) Comparative evaluation of three different methods for $\mathrm{HbAlc}$ measurement with High-performance liquid chromatography in diabetic patients. Adv Biomed Res. 3:94. https://doi.org/10.4103/2277-9175.129364

28. Dijkstra A, Lenters-Westra E, de Kort W, Bokhorst AG, Bilo HJ, Slingerland RJ, Vos MJ (2017) Whole blood donation affects the interpretation of hemoglobin A1c. PLoS One 12(1):e0170802. https ://doi.org/10.1371/journal.pone.0170802

29. Hellman R (2016) When are HbA1C values misleading? AACE Clin Case Rep 2(4):e377-e379. https://doi.org/10.4158/EP161209.CO

30. Cohen RM, Franco RS, Khera PK, Smith EP, Lindsell CJ, Ciraolo PJ, Palascak MB, Joiner CH (2008) Red cell life span heterogeneity in hematologically normal people is sufficient to alter $\mathrm{HbA1c}$. Blood 112(10):4284-4291. https://doi.org/10.1182/blood-2008-04-15411 2

31. Hess JR, Biomedical Excellence for Safer Transfusion (BEST) Collaborative (2012) Scientific problems in the regulation of red blood 
cell products. Transfusion 52(8):1827-1835. https://doi.org/10.111 $1 / \mathrm{j} .1537-2995.2011 .03511 . x$

32. Bosman GJ (2013) Survival of red blood cells after transfusion: processes and consequences. Front Physiol. 2013(4):376. https:// doi.org/10.3389/fphys.2013.00376

33. Luten M, Roerdinkholder-Stoelwinder B, Schaap NP, de Grip WJ, Bos HJ, Bosman GJ (2008) Survival of red blood cells after transfusion: a comparison between red cells concentrates of different storage periods. Transfusion 48(7):1478-1485. https://doi.org/10.1 $111 / \mathrm{j} .1537-2995.2008 .01734 . x$
34. Finotti A, Lamberti N, Gasparello J, Bianchi N, Fabbri E, Cosenza LC, Milani R, Lampronti I, Dalla Corte F, Reverberi R, Manfredini F, Gambari R (2016) Possible detection of Autologous Blood Transfusion (ABT) based on circulating plasma microRNAs involved in erythroid differentiation and fetal hemoglobin induction. Int J Mol Med 38(1):S70-S70

35. Little RR, Roberts WL (2009) A review of variant hemoglobins interfering with hemoglobin A1c measurement. J Diabetes Sci Technol 3(3):446-451. https://doi.org/10.1177/193229680900300307 